\title{
Quantitative measures of sympathetic skin response in diabetes: relation to sudomotor and neurological function
}

\author{
D M Levy, G Reid, D A Rowley, R R Abraham
}

\begin{abstract}
The sympathetic skin response (SSR) at the foot to a deep inspiration was measured in 68 randomly selected diabetic patients and 46 age matched normal subjects and compared with other quantitative measures of neurological and sudomotor function. SSR was obtained in all but three diabetic patients. The upper limit of normal for the onset latency was $2202 \mathrm{~ms}$ and the lower limit for the amplitude of the first wave $92 \mu \mathrm{V}$. Ten diabetic patients had measurable but prolonged latencies, and 11 had measurable but low amplitudes. There were no significant associations between latency, height, and age, but in insulin dependent patients there was a significant diminution of response amplitude with increasing duration of diabetes. Latency was weakly associated with Marstock thermal thresholds, respiratory $R R$ variation, and common peroneal nerve conduction velocity. SSR amplitude was associated with the density of pilocarpine activatable sweatspots in the same region of the foot. Patients with abnormal latencies were significantly older and had reduced thermal sensation than those with normal latencies. Median coefficients of variation for repeat testing in diabetic patients were $9 \%$ for latency and $13 \%$ for amplitude. The test is objective and reproducible, but latency measurements reflect conduction in a long multineuronal pathway and are not purely a measure of peripheral $C$ fibre function; amplitude measurements reflect the density of spontaneously activable sweat glands and are therefore a valid measure of peripheral sympathetic activity, though they depend more on temperature than do latencies (mean change over the range $32-34^{\circ} \mathrm{C} ; 8 \cdot 5 \%{ }^{\circ} \mathrm{C}$ for amplitude, $-2 \cdot 5 \% /{ }^{\circ} \mathrm{C}$ for latency).
\end{abstract}

\section{$(\Im$ Neurol Neurosurg Psychiatry 1992;55:902-908)}

Department of

Diabetes and

Endocrinology,

Central Middlesex

Hospital, Park Royal, London NW10 7NS, UK

D M Levy

G Reid

D A Rowley

R R Abraham

Correspondence to:

Dr Levy

Received 9 May 1991

and in revised form

11 December 1991.

Accepted 30 January 1992 quantitation of distal sympathetic function is of considerable interest in diabetic neuropathy, where peripheral small fibre dysfunction is an important facilitatory factor in the generation of diabetic foot ulceration ${ }^{1}$ and of Charcot joints. ${ }^{2}$ Spinal sympathetic outflow is directed to muscle as muscle sympathetic activity, causing vasodilatation in muscle capillaries, and to skin (skin sympathetic activity), regulating skin blood flow and sweat gland function. Microneurography is able to detect these activities independently, ${ }^{3}$ but it is a difficult technique and cannot be used to study large numbers of subjects. Non-invasive measurements of skin vasoconstriction ${ }^{4}$ have become more practical but are still laborious. The measurement of sympathetic skin activity is technically much simpler, and in recent years there has been a resurgence of interest in this measurement, which was first made over a century ago.

The sympathetic skin response (SSR) is caused by changes in activity of the eccrine sweat glands, and several studies have recently investigated this response in diabetic subjects. $^{5-9}$ In most of these studies, however, the sensitivity of the method and the selection of largely neuropathic patients has allowed the response to be measured only as either present or absent, limiting its value as a quantitative measure of neurological function. The aims of the current study were therefore to develop ways to improve the measurement of SSR, to allow quantitative measurements to be made; to determine the reproducibility of the response and its relation to local skin temperature, physical characteristics, and control of diabetes; to compare SSR with other measurements of distal sudomotor function-activated sweat gland counts and sweat output-in the same patients; and to compare the responses with other measurements of autonomic and peripheral nerve function.

\section{Methods}

SUBJECTS

Sixty eight diabetic patients 66 years of age and under were selected at random from our clinic database of approximately 1400 patients; 46 normal, age matched subjects were also studied. Their clinical characteristics are shown in table 1. Nineteen diabetic patients were considered to have symptomatic autonomic neuropathy, defined as any or all of the following: abnormalities of sweating, symptomatic postural hypotension, gastrointestinal symptoms (excluding simple constipation), and impotence.

Subjects were asked to stop using any skin

preparation on the feet for two weeks before the test. Tests were performed in a warm room, $21-24^{\circ} \mathrm{C}$, with the subject recumbent. Foot temperature was maintained at $32-34^{\circ} \mathrm{C}$, using convective heating if necessary. To ensure that no patient was hypoglycaemic, capillary blood glucose was measured before the test (Glucometer II and Glucostix, Ames, Stoke Poges), 
Table 1 Clinical characteristics of normal and diabetic subjects. Results are mean (SD, range)

\begin{tabular}{lll}
\hline & $\begin{array}{l}\text { Normal subjects } \\
(n=46)\end{array}$ & $\begin{array}{l}\text { Diabetic subjects } \\
(n=68)\end{array}$ \\
\hline Age (years) & $44 \cdot 6(12 \cdot 7,21-79)$ & $41 \cdot 0(15 \cdot 2,17-66)$ \\
Duration of diabetes (years) & $19: 27$ & $12 \cdot 4(9 \cdot 3,1-34)$ \\
Sex (M:F) & & $41: 27$ \\
Type of diabetes: & 42 \\
$\quad$ Type 1 (Insulin dependent) & 26 \\
$\quad$ Type 2 (Non-insulin dependent) & \\
$\quad$ Insulin & & 49 \\
$\quad$ Oral hypoglycaemic & 15 \\
$\quad$ Diet alone & 4 \\
Glycated haemoglobin $(\%)(n=52)$ & $11 \cdot 3(2 \cdot 8,6 \cdot 5-16 \cdot 5)$ \\
Random plasma glucose $(\mathrm{mmol} / \mathrm{l})(\mathrm{n}=42)$ & $10 \cdot 0(4 \cdot 4,3 \cdot 9-19 \cdot 0)$ \\
\hline
\end{tabular}

and venous blood was taken for glucose and glycated haemoglobin (affinity chromatographic method, reference range $<8.0 \%$ ) at the end of testing.

\section{MEASUREMENT OF SSR}

We used a method modified from that of Shahani et al..$^{5}$ Tests were performed on the right leg. All electrodes, apart from the earth, which was a plate EMG electrode attached to the lateral side of the lower leg, were standard $\mathrm{Ag}-\mathrm{AgCl}$ disposable ECG monitoring electrodes (3M Corporation, Minnesota) and recordings were made on a Nicolet Viking electromyograph (Nicolet Medical Instruments, Coventry). We used a deep inspiration as the stimulus, and after a demonstration the subject was allowed to practice this unfamiliar manoeuvre. Intercostal EMG was recorded with two electrodes attached to the right lower lateral chest wall (over 7th-9th intercostal spaces), and SSR with electrodes on the midtarsal portion of the dorsum of the foot and on the sole of the foot immediately opposite the dorsal electrode. Recordings were made simultaneously on two channels, one recording intercostal muscle activity, the other the SSR. The filter settings used were $0.5 \mathrm{~Hz}$ (high pass) and $100 \mathrm{~Hz}$ (low pass). These were chosen as the lowest frequencies available on the Nicolet Viking, though it is likely that the recording would be further improved if an even lower filter frequency were available.

Twelve responses were recorded. To allow

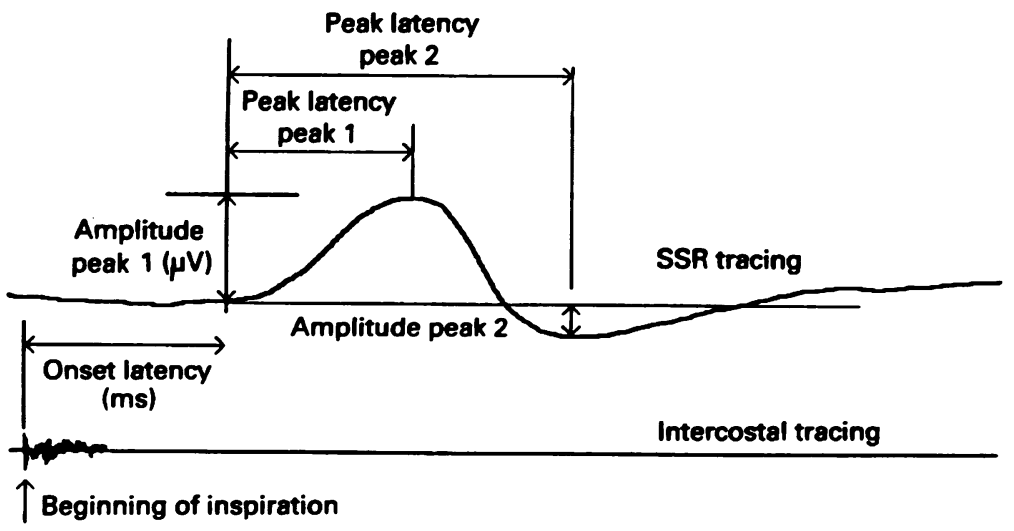

Figure 1 Diagrammatic representation of normal sympathetic skin response; upper trace $=S S R$ measurement, lower trace = intercostal muscle electrode recording. Conventions used for measuring the latencies and amplitudes are shown. for the habituation of the response, stimuli were separated by at least one minute. Tracings were stored on disc for later analysis. Digital averaging was not available on the Viking at the slow sweep speeds used, and each response was analysed individually using electronic cursor placements. The mean of the 12 responses was calculated for the following measurements: (1) onset latency (ms): the time between onset of intecostal activity and first (usually negative) deflection; (2) amplitude $(\mu \mathrm{V})$ : the baselinepeak measurement of the first and second deflections; in some cases third (negative) and fourth (positive) deflections were seen, but not measured. In $10 \%$ of diabetic patients the responses were "inverted" (that is, positive followed by negative wave); in these cases absolute measurements from baseline were used; (3) Peak latency (ms): the time between onset of first deflection and the first and second peaks. Figure 1 shows the conventions used for measuring latencies and amplitudes on a typical tracing.

NEUROPHYSIOLOGICAL TESTS

Each diabetic patient had a range of neurological tests performed. The number undergoing each test was as follows: Marstock thermal thresholds, ${ }^{10} 60$ (88\%); vibration perception thresholds (Biothesiometer), ${ }^{11} 58$ $(85 \%)$; Autonomic function tests ${ }^{12}$-respiratory $\mathrm{RR}$ variation, 60 (88\%), 30:15 (lying: standing) ratio, 61 (90\%), Valsalva ratio, 51 $(60 \%)$; postural blood pressure (random zero sphygmomanometer), 59 (87\%); pilocarpineactivated sweatspot density, ${ }^{13} 53$ (77\%); dynamic acetylcholine sweat output, ${ }^{14} 60$ (87\%); nerve conduction study, ${ }^{15} 35$ (52\%).

Pilocarpine-activated sweatspot density (No/ $\mathrm{cm}^{2}$ ) was measured at the dorsolateral aspect of the foot, using imprints on bromophenol blue indicator papers after pilocarpine iontophoresis ( $1 \%$ in $4 \%$ agar gel at $1.5 \mathrm{~mA}$ for five minutes). Prints were then analysed by computerised image analysis (Quantimet 970, Leica Instruments, Cambridge). Sweat output (mg) over a $1.7 \mathrm{~cm}^{2}$ area of the dorsolateral aspect of the foot was measured for $12 \mathrm{~min}$ after five minutes of acetylcholine iontrophoresis $(1 \%$ in gel at $1.5 \mathrm{~mA})$ using a directly calibrated computerised ventilated capsule sudorometer.

EFFECT OF FOOT TEMPERATURE

The effect of local foot temperature on the response was investigated in four normal men (ages 30-47). The foot was cooled using either cold air or ice packs and rewarmed by convection to $35^{\circ} \mathrm{C}$ over a period of about 30 minutes. Single responses were measured during rewarming at intervals of approximately one minute.

REPRODUCIBILITY

Repeat tests were performed in randomly selected subjects (five normal, five diabetic) 6-12 weeks after the first test.

STATISTICS

Mean onset latency was normally distributed, 
Figure 2 Effect of change in local foot temperature on (a) SSR latency and (b) amplitude in four normal men. Curves of individual subjects were plotted using distance least weighted squares (Systat). Vertical dotted lines represent temperature range study. $\left(32-34^{\circ} \mathrm{C}\right)$ used in clinical
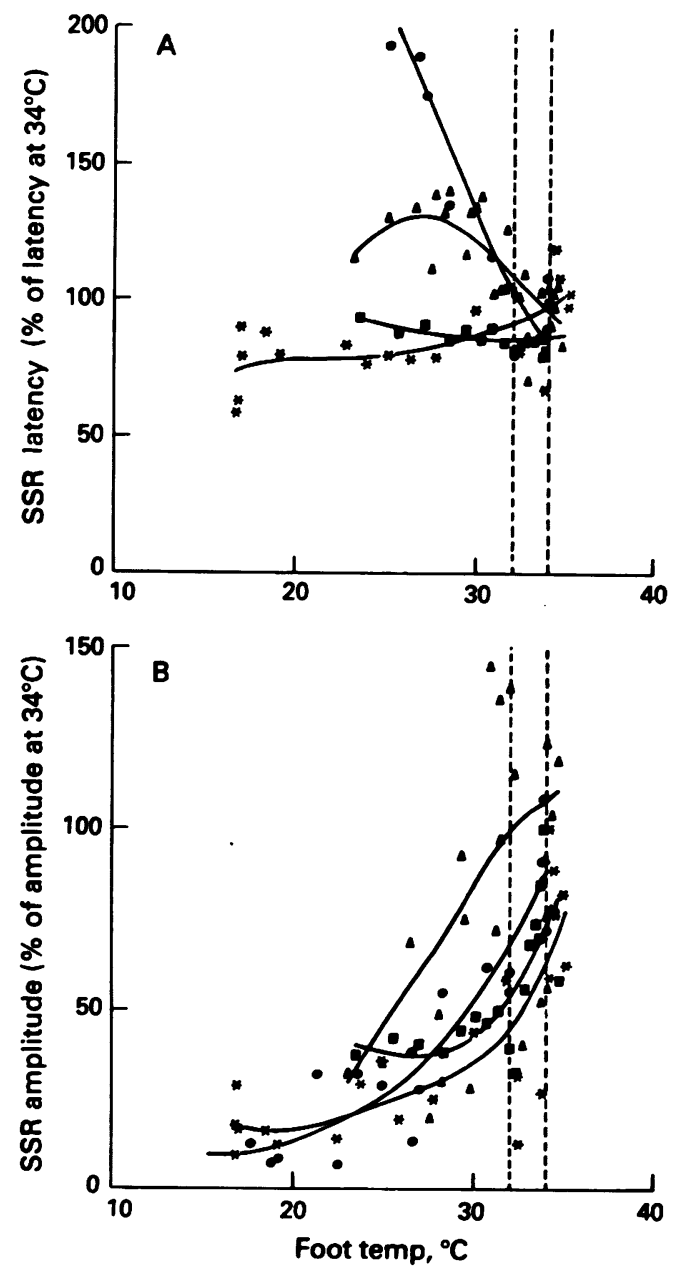

but the mean amplitude of the first and second peaks and mean latencies of the two peaks required log transformation to achieve normality. Student's $t$ test was used for group comparisons, and Pearson correlation coefficients were used. Least squares regression analysis was used to evaluate particular associations, and the non-parametric Mann-Whitney $U$ test was used for subgroup comparisons.

\section{Results}

NORMAL SUBJECTS

Responses were present in all subjects. The

Figure 3 Relation between SSR latency and age in diabetic patients. The weak but statistically significant prolongation of latency with age $(r=$ $0 \cdot 26, p=0.03)$ is further weakened $(r=0.19$, $p=0.13$ ) by the removal of the outlying patient (latency $3265 \mathrm{~ms}$ ). Regression line for the whole group is shown.

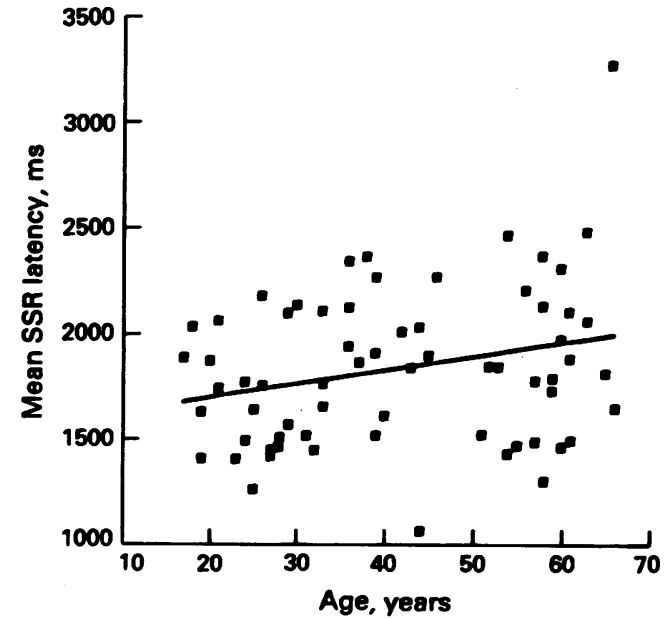

mean onset latency was 1564 (SD 319) ms, the mean peak 1 amplitude 350 (range 87-772) $\mu \mathrm{V}$, and mean peak 2 amplitude 411 (26-2707) $\mu \mathrm{V}$. Mean peak 1 latency was 960 (269) ms and peak 2 latency 2091 (647) ms. Latencies were normally distributed but amplitudes required $\log$ transformation to achieve normality. The upper limit of normal (2 SD above the mean) for onset latency was therefore $2202 \mathrm{~ms}$, for peak 1 latency $1498 \mathrm{~ms}$ and for peak 2 latency 3385 ms. Using log transformed values for the amplitude of peak 1 yielded a lower limit of normal (2 SD below the mean) of $92 \mu \mathrm{V}$. There were no significant differences in responses between male and female subjects (latency, $p=0.41$; amplitude: $\mathrm{p}=0.95$ ).

\section{Associations with age and height}

There was no significant association between onset latency and age $(r=0.17, p=0.26)$ and height $(r=0.14, p=0.52)$, and the amplitude of peak 1 did not change significantly with age $(r=0 \cdot 10, p=0 \cdot 52)$.

\section{Effect of foot temperature}

The results of the warming experiment in four normal subjects are shown in figure 2 . The latency plots show considerable variation between the subjects over the wide temperature range tested. Two subjects showed a decrease in latency over the range $32-34^{\circ} \mathrm{C}$, and the remaining two showed a slight increase. The mean change, calculated as a percentage of the latency at $34^{\circ} \mathrm{C}$, was $-2 \cdot 5 \% /{ }^{\circ} \mathrm{C}$. Amplitudes showed a consistent increase with temperature in all subjects, averaging $8 \cdot 5 \% /{ }^{\circ} \mathrm{C}$ over the same temperature range.

\section{DIABETIC SUBJECTS}

Three diabetic patients had no recordable negative peaks; one of them had recordable positive peaks. When present, onset latency was significantly longer than in the normal group (1836 (269) ms $v 1564$ (319) $\mathrm{ms}$; $\mathrm{p}<0.001)$. Mean amplitudes of the two peaks were significantly lower than in normal subjects (peak $1: 254 \quad(42-671) \quad \mu \mathrm{V} \quad v \quad 350$ (87-772) $\mu \mathrm{V}, \quad \mathrm{p}=0.006$; peak 2: 273 (27-943) $\mu \mathrm{V} v 411(26-2707) \mu \mathrm{V}, \mathrm{p}=0.04)$ The latency of peak 1 , but not peak 2 , was increased (1255 (611) ms $v 960$ (269) ms, $\mathrm{p}=0.01$ ).

Ten patients had a prolonged onset latency; after the three patients with an absent response were included, this yielded an abnormality rate for latency of $19 \%$. One of these patients, a very tall $(189 \mathrm{~cm}) 66$ year old non-insulin dependent patient, had a dramatically prolonged onset latency (3265 ms). Figure 3 shows that this patient appreciably affected the relation between onset latency and age, and this result was excluded from further analysis. Fourteen patients had low peak 1 amplitude, giving an overall abnormality rate for this measurement of $25 \%$. Only five patients had an abnormal onset latency together with a low peak 1 amplitude. Eleven patients had prolonged latency of peak 1 , yielding a similar 
Figure 4 SSR amplitude shows a weakly significant negative correlation with known duration of diabetes in insulin dependent diabetic patients: $r=-0.42, n=37$ $p<0.001$.

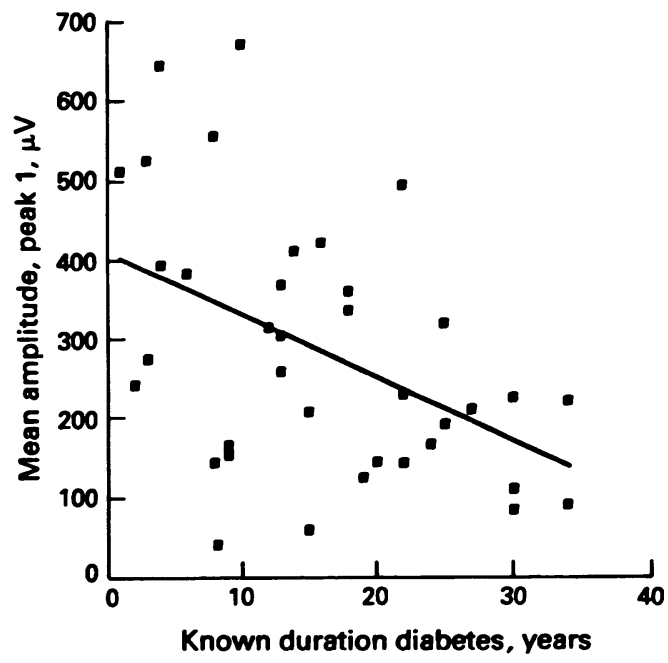

abnormality rate $(21 \%)$. The peak amplitudes were negatively correlated with onset latency (peak 1: $\mathrm{r}=0.25, \mathrm{p}=0.05 ;$ peak 2: $\mathrm{r}=0.28, \mathrm{p}=0.03)$.

Associations with age, height, duration of diabetes, diabetic control, and sex

As in normal subjects, there was no change in onset latency with age $(r=0 \cdot 19, p=0 \cdot 13)$ after the patient discussed above was excluded. Amplitudes of peaks 1 and 2 decreased with age (peak 1: $\mathrm{r}=-0.47, \mathrm{p}<0.001$; peak 2 : $r=-0.23, p=0.06)$. In the whole group, no measurements were related to known duration of diabetes, but onset latency increased with duration of diabetes in insulin dependent subjects $(r=0.29, n=38, p=0.07)$ and the amplitude of peak 1 decreased significantly $(\mathrm{r}=-0.42, \mathrm{n}=38, \mathrm{p}<0.001$ ) (fig 4). When the tall elderly neuropathic patient was excluded, there was no significant association between onset latency and height $(r=0 \cdot 14$, $\mathrm{p}=0 \cdot 29)$. Blood glucose and glycated haemoglobin were not associated with any of the measurements. Latencies were significantly longer in men than in women (1927 (356) ms $v 1695$ (355) ms, $\mathrm{p}=0.01$ ), but amplitudes were similar (251 (42-671) $\mu \mathrm{V} v 259$ (53-643) $\mu \mathrm{V}, \mathrm{p}=0.05)$.

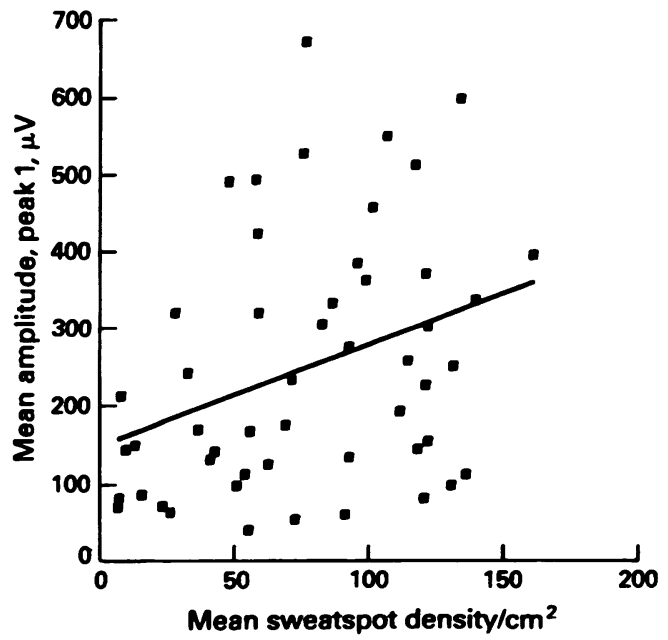

Associations with other neurological measurements

Sudomotor function-Onset latency was not significantly associated with either pilocarpine activated sweatspot density or the dynamic acetylcholine sweat response (mean sweatspot density: $\mathrm{r}=-0.07, \mathrm{p}=0.63$; acetylcholine sweat output: $r=0.02, p=0.85$ ). However, the peak amplitudes were significantly associated with mean sweatspot density (peak 1: $r=0.32, p=0.02$ (fig 5); peak 2: $r=0.27$, $\mathrm{p}=0.03$ ).

Measurements reflecting small fibre functionWarm thermal thresholds were weakly associated with onset latency $(r=0.23, p=0.07)$ but rather more strongly associated with amplitude of peaks 1 and 2 (both, $r=-0 \cdot 27$, $p=0.02)$. Respiratory $R R$ variation was associated with onset latency $(r=-0.26$, $\mathrm{p}=0.05)$, peak 1 amplitude $(\mathrm{r}=0.51$, $\mathrm{p}<0.0001)$, and peak 2 amplitude $(r=0.35$, $p=0.008)$. There were no significant associations with the Valsalva ratio, $30: 15$ ratio, or postural change in blood pressure.

Large fibre tests-There were no significant associations with vibration perception thresholds, but there were weak associations with electrophysiological measurements (common peroneal motor conduction velocity and SSR latency: $r=-0.44, p=0.01$; shortest $f$ latency and SSR latency: $r=0.40, p=0.05$; sural action potential amplitude (SSAP) and SSR latency: $r=-0.37, p=0.06$; SSAP and SSR amplitude: $r=0.41, p=0.03$ ).

Reproducibility-Median coefficient of variation for onset latency was $16 \%(2-22 \%)$ in normal subjects and $9 \%(4-14 \%)$ in diabetic patients. Corresponding results for peak 1 amplitude were $30 \%(13-44 \%)$ in normal subjects and $13 \%(3-69 \%)$ in diabetic patients.

CHARACTERISTICS OF PATEINTS WITH ABNORMAL RESPONSES

The 13 patients with prolonged or unmeasurable latencies were significantly older than those with normal latencies (54 v 36 years, $\mathrm{p}=0.02$ ) (table 2). Nineteen patients (14 men) had symptomatic autonomic neuropathy. Where recordable, onset latency was significantly longer in symptomatic than in asymptomatic patients (1976 (1069-3265) ms $v 1755$ (1266-2488) ms, $\mathrm{p}=0.03)$, and the amplitude of peak 1 was lower $(142(64-524) \mu \mathrm{V} v$ 240 (42-671) $\mu \mathrm{V}, \mathrm{p}=0.04)$.

\section{Discussion}

This study has shown that, by using appropriate techniques, sympathetic skin responses can be measured in almost all $(96 \%)$ of a group of randomly selected diabetic patients; this represents a higher detection rate than distal sensory electrophysiological measurements, such as the sensory action potential amplitude of the medial plantar nerve. ${ }^{16}$ The ability to quantify responses, rather than recording them as either present or absent, and to define reference ranges significantly enhances the use of this technique as a measurement of nerve 
Table 2 Comparison of diabetic patients with absent or prolonged ( $>2202 \mathrm{~ms})$ mean onset latency $(n=13)$ and those with normal latencies $(n=55)$. Data are presented as median (range)

\begin{tabular}{|c|c|c|c|}
\hline & Abnormal latency & Normal latency & pValue * \\
\hline $\begin{array}{l}\text { Age (years) } \\
\text { Duration of diabetes (years) }\end{array}$ & $\begin{array}{c}54(23-66)(\mathrm{n}=13) \\
5 \cdot 5(1-30)(\mathrm{n}=13)\end{array}$ & $\begin{array}{l}36(17-66)(\mathrm{n}=55) \\
12 \cdot 5(1-34)(\mathrm{n}=55)\end{array}$ & $\begin{array}{l}0.02 \\
0.33\end{array}$ \\
\hline \multicolumn{4}{|l|}{ Type of diabetes: } \\
\hline $\begin{array}{l}\text { Type } 1 \text { (Insulin dependent) } \\
\text { Type } 2 \text { (Non-insulin dependent) }\end{array}$ & 6 & $\begin{array}{l}40 \\
16\end{array}$ & \\
\hline Height (cm) & $166(155-188)(n=13)$ & $\begin{array}{l}16 \\
168(151-191)(\mathrm{n}=53)\end{array}$ & \\
\hline Respiratory $R R$ variation (bpm) & $8(2-37)(n=12)$ & $\begin{array}{c}168(151-191)(\mathrm{n}=53) \\
21(3-45)(\mathrm{n}=48)\end{array}$ & $\begin{array}{l}0 \cdot 88 \\
0.02\end{array}$ \\
\hline Valsalva ratio & $1.52(1.07-2.24)(\mathrm{n}=10)$ & $1.69(1.09-2.95)(n=41)$ & 0.17 \\
\hline 30:15 Ratio & $1.07(0.98-1.37)(\mathrm{n}=12)$ & $1 \cdot 10(0.96-1.64)(\mathrm{n}=49)$ & 0.09 \\
\hline Systolic BP fall (mm Hg) & $6 \cdot 5(-9-22)(n=10)$ & $2 \cdot 0(-16-24)(n=48)$ & $0 \cdot 13$ \\
\hline Marstock warm threshold $\left({ }^{\circ} \mathrm{C}\right)$ & $12 \cdot 2(4 \cdot 9-16 \cdot 2)(\mathrm{n}=12)$ & $6 \cdot 4(2 \cdot 4-16 \cdot 2)(n=50)$ & 0.006 \\
\hline Marstock cool threshold $\left({ }^{\circ} \mathrm{C}\right)$ & $5 \cdot 6(1.4-12 \cdot 0)(n=12)$ & $2 \cdot 5(1 \cdot 1-12 \cdot 7)(n=49)$ & $0 \cdot 20$ \\
\hline $\begin{array}{l}\text { Marstock heat pain threshold }\left({ }^{\circ} \mathrm{C}\right) \\
\text { Vibration threshold }(\mathrm{V})\end{array}$ & \multicolumn{2}{|c|}{ Vibration threshold (V) } & 0.69 \\
\hline Great toe & $19.5(10.5-45)(n=9)$ & $10 \cdot 0(3 \cdot 5-34 \cdot 3)(n=40)$ & 0.005 \\
\hline Malleolus & $18 \cdot 4(10 \cdot 0-32 \cdot 7)(\mathrm{n}=9)$ & $11.3(3.8-48 \cdot 0)(\mathrm{n}=49)$ & 0.06 \\
\hline Common peroneal conduction velocity $(\mathrm{m} / \mathrm{s})$ & $43.8(26 \cdot 0-49 \cdot 6)(\mathrm{n}=10)$ & $46 \cdot 0(31 \cdot 0-52 \cdot 0)(\mathrm{n}=28)$ & $0 \cdot 19$ \\
\hline Sural sensory action potential $(\mu \mathrm{V})$ & $3.9(1.5-21 \cdot 8)(\mathrm{n}=8)$ & $12.9(5 \cdot 7-28 \cdot 2)(\mathrm{n}=24)$ & 0.01 \\
\hline \multicolumn{4}{|l|}{ Sweat measurements } \\
\hline $\begin{array}{l}\text { Sweat volume }(\mathrm{mg}) \\
\text { Mean sweatspots }\left(\mathrm{No} / \mathrm{cm}^{2}\right)\end{array}$ & $\begin{array}{l}1 \cdot 51(0 \cdot 17-4 \cdot 16)(\mathrm{n}=12) \\
43(7-136)(\mathrm{n}=11)\end{array}$ & $\begin{array}{l}2 \cdot 20(0 \cdot 68-6 \cdot 12)(\mathrm{n}=49) \\
85(7-161)(\mathrm{n}=42)\end{array}$ & $\begin{array}{l}0 \cdot 10 \\
0 \cdot 13\end{array}$ \\
\hline
\end{tabular}

function. The logarithmic distribution of SSR amplitudes in normal subjects means that after appropriate transformation the lower limit of the reference range ( $2 \mathrm{SD}$ below the mean) does not include an absent response. When present, latency measurements were longer and response amplitudes smaller in diabetic subjects than in normal subjects of a comparable age. Test-retest reproducibility was similar to that of other neurological measurements in diabetic neuropathy, though appreciably higher for SSR amplitude than for the latency, and larger in diabetic than normal subjects. It is of interest that a microneurographic study found that, although mean integrated neural activity varied with the type of stimulus used, amplitudes were relatively constant, the most important factor being that the stimuli should be delivered randomly in time. ${ }^{17}$

The increased detection rate in this study compared with other reports may be due to the population studied, in particular its relatively young mean age and short duration of diabetes. In most previous reports, SSR has been studied in patients with symptomatic neuropathy, instrumental evidence of peripheral neuropathy, or both; consequently the prevalence of undetectable responses has been reported as $40-83 \%$. One recent study detected the response in the arm in all but $9 \%$ of subjects but did not study the leg, where peripheral neuropathy is more severe. ${ }^{8}$ In addition to patient selection, however, three technical factors may have influenced our results. Firstly, we used the lowest available cutoff frequency for the high pass filter; the higher settings used in previous studies would tend to decrease the response amplitude. Secondly, we used a deep inspiration rather than electrical nerve trunk stimulation; Shahani et al found that using the inspiration yielded responses of larger amplitude than direct electrical stimulation. ${ }^{5}$ Thirdly, proprietary disposable electrodes seem to give larger and more consistent responses than conventional EMG metal plate electrodes, probably as a result of consistency in their manufacture and electrolyte composition. Our results for both latency and amplitude measurements differ from those of previous studies, again probably as a result of methodological differences.

Increases in local foot temperature resulted in consistent increases in amplitude over a wide temperature range $\left(15-35^{\circ} \mathrm{C}\right)$. Over the range used in the clinical study $\left(32-34^{\circ} \mathrm{C}\right)$ the mean change per ${ }^{\circ} \mathrm{C}$ was $8.5 \%$ of the amplitude at $34^{\circ} \mathrm{C}$. This increase is presumably due to increased release of neurotransmitters at the neuroglandular junction. The changes in latency were less consistent and may reflect subtle effects of profound cooling of the foot on central pathways which are represented in the latency measurement. Changes were similar in magnitude to those of motor nerve conduction velocities-approximately $2 \% /{ }^{\circ} \mathrm{C}$ $\left(1 \mathrm{~ms} /{ }^{\circ} \mathrm{C}\right) .{ }^{18}$ The behaviour of SSR responses with changing temperature deserves further investigation, but this study confirms that the changes in latency are less noticeable than those of amplitude. Careful control of foot temperature would be an important consideration in longitudinal studies using amplitude measurements.

We have not found a significant association between height and onset latency of the SSR in normal or diabetic subjects, confirming the finding of Knezevic and Bajada. ${ }^{6}$ Shahani et al found that latency correlated well with the subject's height, ${ }^{5}$ though the relation was statistically weak and is much weaker than other measures of nerve conduction velocity (such as peroneal motor nerve conduction and f latency). This again probably reflects the complexity of the neurological pathway of the SSR, particularly the ill defined preganglionic portion, and the slow postganglionic conduction. ${ }^{19}$ There is also a slight diminution of SSR amplitude with age in diabetic patients. This can be explained on the basis of a decrease with age in the number of pilocarpine activatable sweat glands in diabetic subjects. ${ }^{12}$ The association suggests that the response amplitude of the first negative wave reflects functioning sweat gland density.

Of the 13 patients with an absent or pro- 
longed onset latency, all but three had abnormal Marstock warm thresholds, though five had normal respiratory $R R$ interval variation. However, seven had three abnormal cardiovascular vagal autonomic tests, though of these only one had symptomatic autonomic neuropathy. The rate of abnormality in the whole group was lower than that for thermal threshold testing ( $31 \%$ for warm thresholds). Several factors may be responsible for this difference: registration of the SSR requires a coordinated sweat gland response, and the efferent pathway to a large group of glands probably has to be damaged substantially in order to delay the onset of the response. An abnormal psychophysical threshold, on the other hand, may occur when there are minimal abnormalities of temporal or spatial summation of impulses.

Shahani et al suggested that the SSR reflects abnormal small fibre function in predominantly axonal neuropathies, rather than clinically disorderd autonomic function. ${ }^{5}$ This is to be expected, since most symptoms of autonomic dysfunction in diabetes are due to abnormalities of proximal parasympathetic rather than of distal sympathetic function, symptoms of which (postural hypotension, gross abnormalities of sweating) are late features of diabetic neuropathy. In fact, the association between SSR, thermal and pain sensation, and the other sweat tests (apart from the association between peak 1 amplitude and pilocarpine activatable sweatspot density) was poor, reflecting the fact that local sweat tests assess function of postganglionic sympathetic nerve terminals and sweat gland receptors, and it is unlikely that their function changes together with that of the whole sympathetic pathway. There was also a poor association with the largely parasympathetic cardiac autonomic function tests, though the association with the most reproducible of the tests, respiratory $R R$ variation, just reached statistical significance. The lack of association with postural changes in blood pressure is unexpected and at variance with the report of Watahiki et al ${ }^{9}$ probably as result of the variability and lack of standardisation of measurements.

Maselli et al found high concordance between an absence of SSR and of sweating after axon reflex stimulation by acetylcholine (quantitative sudomotor axon reflex test, Q-SART $^{20}$ ), ${ }^{7}$ but this finding does not support their conclusion that the combined use of these two tests may help uncover early distal sympathetic failure. Both tests would be expected to have abnormal results in patients selected on the basis of abnormal peripheral nerve function, and although the Q-SART may be a sensitive indicator of sympathetic dysfunction, it has not been studied in randomly selected diabetic subjects nor compared with other standard neurophysiological measurements currently in use. Our study confirms the views of both Shahani et $a l^{521}$ and Fagius and Wallin $^{22}$ that abnormal sympathetic skin activity is a manifestation of relatively advanced neuropathy. The ability to quantify SSR latency allows us to extend Fagius and Wallin's view that sympathetic failure is an "all or none" phenomenon, on the basis that they were unable to find evidence of slowed sympathetic conduction in individual microneurographic recordings. ${ }^{22}$ They suggested that conduction was maintained at relatively normal levels until, finally, conduction block supervened and the function of that fibre failed. Our finding of a group of patients with detectable but significantly prolonged SSR latencies is presumptive evidence of slowed sympathetic conduction in an integrated pathway, even though there may be "all or none" failure in individual sympathetic fibres. Follow up of these patients with prolonged latencies would be required to confirm this.

In summary, this study has confirmed that if attention is paid to methodological detail, SSR can be quantified in most diabetic patients. Latency measurement is an objective and reproducible measure of conduction in a long multineuronal pathway and may therefore be complementary to semiquantitative psychophysical measurements. In itself, measurement of SSR amplitude seems to be no more sensitive than other measurements as a diagnostic tool in diabetic neuropathy, but it has acceptable reproducibility and can be easily measured in the EMG laboratory; we have confirmed that it is a valid measure of sweat gland innervation. Like other neurophysiological measurements, however, it varies with surface temperature, and alternative, more direct measures of peripheral sympathetic innervation may be preferable for detailed diagnosis.

We are grateful to Dr Raju Abraham, consultant neurophysiologist, for the use of the EMG equipment, and Dr Peter Frost, consultant chemical pathologist, Central Middlesex Hospital, for the glucose and glycated haemoglobin assays. Dr Stuart McHardy-Young and Dr Ewart Jepson kindly allowed us to study their patients. Leica Instruments (Cambridge) allowed us use of their Quantimet 970 image analyser for the sweatspot analyses.

1 Ahmed ME, Le Quesne PM. Quantitative sweat test in diabetic with neuropathic foot lesions. $\mathcal{F}$ Neurol Neurosurg Psychiatry 1986;49:1059-62.

2 Watkins PJ, Edmonds ME. Sympathetic nerve failure in diabetes. Diabetologia 1983;25:73-7.

3 Wallin BG. Intraneural recordings of normal and abnormal sympathetic activity in man. In: Bannister R, ed. Autonomic failure: a textbook of disorders of the autonomic nervous nomic failure: a textbook of disorders of the autonomic nervous
system. Oxford: Oxford University Press, 1988:177-95.

4 Gilmore JE, Allen JA, Hayes JR. A comparison of peripheral vasoconstrictor responses and cardiovascular autonomic function tests in diabetic patients. Diabetologia 1990; 33:350-6.

5 Shahani BT, Halperin JJ, Boulu P, Cohen J. Sympathetic skin response-a method of assessing unmyelinated axon dysfunction in peripheral neuropathies. $\mathcal{F}$ Neurol Neurosurg Psychiatry 1984;47:536-42.

6 Knezevic W, Bajada S. Peripheral autonomic surface potential. A quantitative technique for recording sympathetic conduction in man. $\mathcal{F}$ Neurol Sci 1985;67:239-51.

7 Maselli RA, Jaspan JA, Soliven BC, Green AJ, Spire J-P, Arnason BGW. Comparison of sympathetic skin response with quantitative sudomotor axon reflex test in diabetic with quantitative sudomotor axon reflex test
neuropathy. Muscle Nerve 1989;12:420-3.

8 Niakan E, Harati Y. Sympathetic skin response in diabetic peripheral neuropathy. Muscle Nerve 1988;11:261-4.

9 Watahiki Y,Baba M, Matsunaga M, Takebe K, Onuma T. Sympathetic skin response in diabetic neuropathy. Elec10 tromyogr Clin Neurophysiol 1989;29:155-9.

Levy D, Abraham R, Reid G. A comparison of two methods for measuring thermal thresholds in diabetic neuropathy. f Neurol Neurosurg Psychiatry 1989;52:1072-7.

11 Bloom S, Till S, Sonksen P, Smith S. Use of a biothesiometer to measure individual vibration thresholds and their variation in 519 non-diabetic subjects. BMF 1984; 
diabetic autonomic neuropathy. BMf 1982;285:916-8.

13 Levy DM, Rowley DA, Abraham RR. Changes in cholinergic sweat gland activation in diabetic neuropathy identified by computerised sweatspot analysis. Diabetologia 1991;34:807-12.

14 Levy DM, Reid G, Abraham RR, Rowley DA. Assessment of basal and stimulated sweating in diabetes using a direct-reading computerized sudorometer. Diabetic Med direct-reading com

15 Abraham RR, Abraham RM, Wynn V. Autonomic and electrophysiological studies in patients with signs or symptoms of diabetic neuropathy. Electroencephalogr Clin Neurophysiol 1986;63:223-30.

16 Levy DM, Abraham RR, Abraham RM. Small- and largefibre involvement in early diabetic neuropathy: a study with the medial plantar response and sensory thresholds. Diabetes Care 1987;10:441-7.

17 Satchell PM, Seers CP. Evoked skin sympathetic nerve responses in man. $\mathcal{F}$ Neurol Neurosurg Psychiatry 1987;
50:1015-21.

18 Halar EM, DeLisa JA, Brozowich FV. Nerve conduction velocity: relationship of skin, subcutaneous and intramuscular temperature. Arch Phys Med Rehabil 1980;61: 199-203.

19 Low PA. Quantitation of autonomic responses. In: Dyck PJ, Thomas PK, Lambert EH, Bunge R, eds. Peripheral neuropathy. Vol 1, 2nd ed. Philadelphia: W B Saunders, 1983:1139-64.

20 Low PA, Caskey PE, Tuck RR, Fealey RD, Dyck PJ Quantitative sudomotor axon reflex test in normal and neuropathic subjects. Ann Neurol 1983;14:573-80.

21 Shahani BT, Day TJ, Cros D, Khalil N, Kneebone CS. RR interval variation and the sympathetic skin response in the assessment of autonomic function in peripheral neuroassessment of autonomic function in

22 Fagius J, Wallin BG. Sympathetic reflex latencies and conduction veocities in normal man. $\mathcal{f}$ Neurol Sci 1980;47:433-8

\section{The Anatomy Lesson of Dr Joan Deyman, by Rembrandt (1606-69)}

On the 8 November 1723 the greater part of this painting was destroyed by fire. The dead man in the picture was Joris Fonteijn, known as black Jan, a thief condemned to death on 27 January 1656, and buried on 2 February. That year Rembrandt was commissioned by the surgeons' guild to paint The Anatomy Lesson of Dr Joan Deyman, the same year he applied for cessio bonorum, a form of bankruptcy.

As was usual in such dissections, Deyman has removed the stomach and intestines before beginning the dissection of the brain. The top of the skull is held by the assistant, Gysbrecht Matthijsz Calcoen, a master of the Amsterdam guild of surgeons, and Deyman is in the course of removing the falx cerebri of the dura mater.

This painting was to be placed in the Anatomy Theatre in Amsterdam which was constructed in 1639 in the attic storey of a small meat market building that was used until 1690. The records of the Anatomy Theatre in Amsterdam state that "on January 28th 1656, there was punished Joris Fonteijn of Diest, who by the worshipful lords of the law court was granted to us an anatomical specimen. On the 29th Dr Joan Deyman made his first demonstration on him in the Anatomy Theatre, three lessons altogether". The entry also notes that Dr Deyman was presented with six silver spoons worth 31 guilders and 19 stuivers in recompense for his three demonstrations.
From 1690 until 1841 the painting hung in the surgeons' guild room in the Nieuwe Waag where it was badly damaged by fire. It subsequently passed through several hands and for a period was in the South Kensington Museum in London. It is presently owned by the city of Amsterdam and can be seen in the Rijksmuseum.

The painting is shown on stamps issued by the Republic of Togo in 1968 (Stanley Gibbons 598 and 600, Scott 648 and C93).

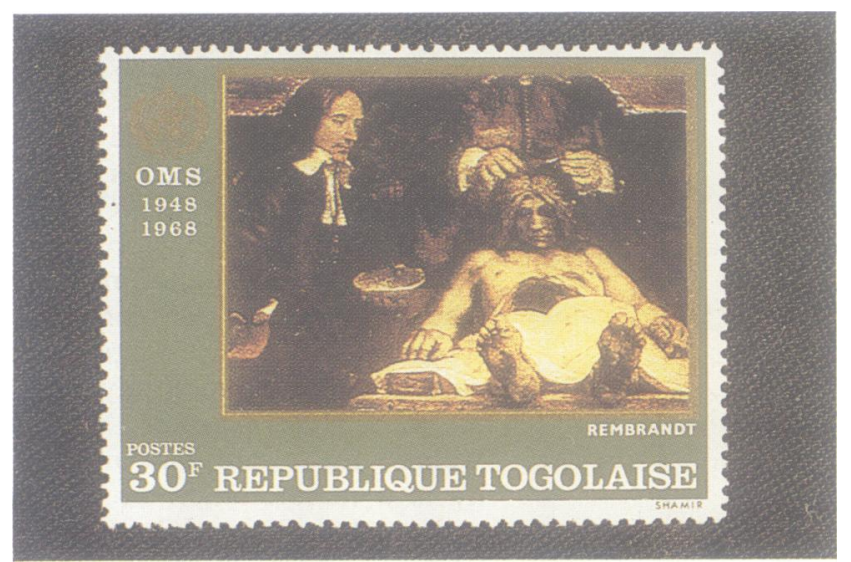

